Check for updates

Cite this: RSC Adv., 2019, 9, 1671

Received 27th November 2018 Accepted 26th December 2018

DOI: 10.1039/c8ra09755k

rsc.li/rsc-advances

\section{Preparation of novel 1,2,3-triazole furocoumarin derivatives via click chemistry and their anti-vitiligo activity}

\author{
Chao Niu, ${ }^{\text {ab }}$ Xueying $\mathrm{Lu}^{\mathrm{ab}}$ and Haji Akber Aisa (D) *ab
}

The extracts of Psoralea corylifolia L. were often used for the repigmentation of leukoderma (vitiligo) in traditional Uygur medicine thousands years ago. Nowadays, its active ingredient, furocoumarins, has been clinically applied since it exhibited strong photosensitivity. Thus, a new series of furocoumarin derivatives (8a-8o) containing 1,2,3-triazole were designed and synthesized based on our previous work. After biological evaluation for melanin contents and tyrosinase activity in B16 murine cells, the SAR was summarized. The results indicated that five compounds $(8 \mathrm{a}, 8 \mathrm{j}, 8 \mathrm{~m}-\mathbf{8 0})$ were more potent than the positive control (8-MOP) on melanogenesis. Among them, $8 \mathrm{a}$ and 80 showed the best stimulating effect on tyrosinase activity as well, and were submitted for further pharmacological study of anti-vitiligo.

\section{Introduction}

Vitiligo is an acquired pigmentary disorder of the skin characterized by circumscribed depigmented macules due to the destruction of the melanocyte and subsequent obstruction of melanin synthesis (Fig. 1). ${ }^{\mathbf{1}, 2}$ The prevalence of vitiligo is often referred to as $0.5-2 \%$ of the world's population. ${ }^{3}$ The origin of vitiligo is thought to be a complex interplay of genetics, environment, oxidative stress, and autoimmunity. ${ }^{4,5}$ And the autoimmune theory is the leading hypothesis that is supported by strong evidence. ${ }^{6}$

In humans, melanin is the primary determinant of skin color and thought to protect skin cells from UVB radiation damage, reducing the risk of cancer. ${ }^{7}$ It is produced by melanocytes which are found in the basal layer of the epidermis and regulated by enzymatic cascade, including tyrosinase (TYR), tyrosinase-related protein 1 (TRP-1) and tyrosinase-related protein 2 (TRP-2). ${ }^{8}$ Among them, TYR is the rate-limiting enzyme and is mainly involved in two distinct reactions of melanin synthesis: firstly, the hydroxylation of a monophenol and secondly, the conversion of an $o$-diphenol to the corresponding $o$-quinone., ${ }^{\mathbf{9}, 10}$

Presently, there are several drugs used for the treatment of vitiligo including photosensitizer (8-MOP, khellin), topical corticosteroids (dexamethasone), calcineurin inhibitors (tacrolimus), vitamin D3 analogs (tacalcitol), ${ }^{\mathbf{1 1}}$ and JAK inhibitors

${ }^{a}$ Key Laboratory of Plant Resources and Chemistry of Arid Zone, Xinjiang Technical Institute of Physics and Chemistry, Chinese Academy of Sciences, Urumqi 830011, China.E-mail: haji@ms.xjb.ac.cn

${ }^{b}$ State Key Laboratory Basis of Xinjiang Indigenous Medicinal Plants Resource Utilization, Xinjiang Technical Institute of Physics and Chemistry, Chinese Academy of Sciences, Urumqi 830011, China (ruxolitinib, baricitinib, tofacitinib) (Fig. 2), which are often used for myelodysplastic disorders, were recently proven to be efficacious for vitiligo based on a large number of clinical cases. $^{12,13}$

Traditional Chinese medicine is an important source of modern drugs. In Uygur medicine, the extract of Psoralea corylifolia L. (Fig. 3) was often used for repigmentation of vitiligo with natural sunlight and initially recorded in 'Yao Yong Zong $\mathrm{Ku}$ ' around 300 years ago. Its active ingredient,

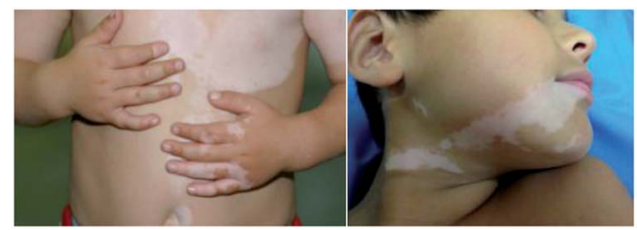

Fig. 1 Vitiligo with typical lesions of the face and trunk.

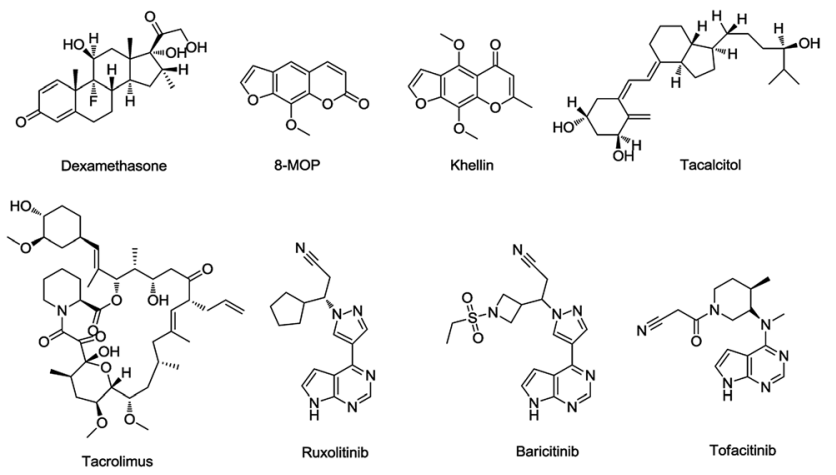

Fig. 2 Structures of commonly used drugs for vitiligo. 


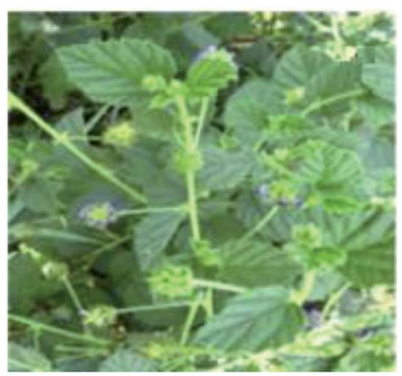

Fig. 3 The plant of the Psoralea corylifolia L.<smiles>COc1c2occc2cc2ccc(=O)oc12</smiles>

8-MOP

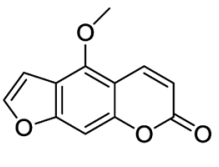

5-MOP

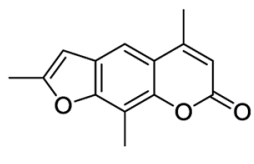

TMP
Fig. 4 The structures of the furocoumarins used for vitiligo.

furocoumarins, has been clinically applied, including 8methoxypsoralen (8-MOP), 5-methoxypsoralen (5-MOP) and 4,5,8-trimethylpsoralen (TMP) (Fig. 4). Further research proved that these compounds exhibited strong photosensitivity, ${ }^{\mathbf{1 4}}$ which may be beneficial for the repigmentation of skin with subsequent exposure to long-waved ultraviolet radiation. ${ }^{\mathbf{1 5}}$ In spite of some undesired side effects, ${ }^{\mathbf{1 6 , 1 7}}$ the therapy is still the most effective way to treat the disease today.

Unfortunately, the targets of furocoumarin for the therapies was still unknown due to the complexity of pathogenesis, and few derivatives with anti-vitiligo activity were reported. ${ }^{\mathbf{1 8 - 2 0}}$ During past few years, many molecules with superior effect on melanogenesis and tyrosinase activity were isolated or synthesized by our group. ${ }^{21-24}$ The preliminary SAR of furocoumarins on vitiligo was outlined in Fig. 5 based on these studies.

1,2,3-Triazole and its derivatives showed particular promise as amide bond isosteres, given their diverse biological properties and facile synthesis from readily available azide and alkyne. ${ }^{25-28}$ The moiety is stable to metabolic degradation and capable of hydrogen bonding, which could be favorable in binding of biomolecular targets and increasing water solubility. ${ }^{29}$

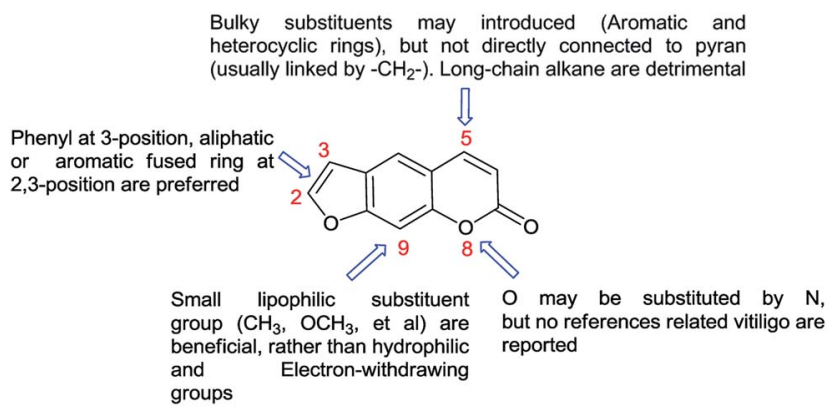

Fig. 5 The SAR of furocoumarins on vitiligo.
As depicted in Fig. 5, it is quite clear that more structure modification should be proceed on C-5 position of the furocoumarin to improve this efficiency. Thus, a new series of derivatives containing 1,2,3-triazole group was synthesized, which may be developed as better candidates for the vitiligo.

\section{Results and discussion}

\subsection{Chemistry}

The synthetic route for the target compounds is outlined in Scheme 1. First, the commercially available material resorcine was converted to the desired intermediate 4-methylumbelliferone 1 at a $92 \%$ yield via Pechmann reaction. ${ }^{30,31}$ Then, Williamson reaction between $\mathbf{1}$ and 2-bromoacetophenone in the presence of potassium carbonate afforded intermediate 2 , which was cyclized in $4 \% \mathrm{KOH}$ ethanolic solution to form $3 .^{32}$ Selenium dioxide was applied in selective oxidation of compound 3 to produce 5-carbaldehyde 4. After that, it was further reduced with $\mathrm{NaBH}_{4}$ to achieve alcohol 5 in 76\% yield. ${ }^{33,34}$ Bromination and azidation of hydroxy with $\mathrm{PBr}_{3}$ and $\mathrm{NaN}_{3}$ successively gave the key intermediate 7. Finally, compound 7 was converted to the target 8a-80 through click chemistry with different alkyne $\mathbf{a}-\mathbf{o} .^{35}$

\subsection{Biological evaluation}

Compounds 8a-8o were evaluated for their activity on melanin synthesis in murine B16 cells, with a known method. ${ }^{36}$ According to the results in Fig. 6, the reference drug 8-MOP enhanced the melanin synthesis by $126.03 \pm 2.97 \%$ at $50 \mu \mathrm{m}$ as compared to the blank control. Most of synthesized compounds could increase the melanin content, especially for $\mathbf{8 a}, \mathbf{8 j}, \mathbf{8 m - 8 0}$, which were more potent than the positive control (8-MOP) with a value from $134 \%$ to $211 \%$. For example, derivatives bearing EDG (81-80) on benzene exhibited a stronger effect than unsubstituted 8k. The $\mathrm{OCH}_{3}$ group contributed more than $\mathrm{CH}_{3}$ to the activity, such as $\mathbf{8 0}>\mathbf{8 m}, \mathbf{8 n}>\mathbf{8 1}$. And it seemed that the para-position may be superior for the substituent to improve melanin synthesis $(\mathbf{8 m}>\mathbf{8 1}, \mathbf{8 0}>\mathbf{8 n})$. Among these halogenated derivatives $(\mathbf{8 a}-\mathbf{8 j})$, ones with $-\mathrm{Cl}$ and $-\mathrm{Br}$ showed higher activity compared with $-\mathrm{F}(\mathbf{8 a}, \mathbf{8 j}>\mathbf{8 g}, \mathbf{8 b}>\mathbf{8 h})$. The position of the halogen on benzene also played an important role for their efficacy, the shift of $-\mathrm{Cl}$ substituent from the para- $(\mathbf{8 a}, 166 \%)$ into the ortho- or meta-position led to $\mathbf{8 b}(118 \%)$ or $8 \mathbf{c}(106 \%)$ separately, which induced a decreased value in melanin content. The similar result was observed in compounds $\mathbf{8 g}$ and $\mathbf{8 h}$, substituted with -F group as well. However, introduction of a second $-\mathrm{F}$ or $-\mathrm{Cl}$ to the benzene may not strengthen this ability $(\mathbf{8 a}>\mathbf{8 d}-\mathbf{8 f}, \mathbf{8 g}>\mathbf{8 i})$, and it is apparent that the presence of a halogen group in the para-position of the phenyl ring was crucial for melanogenesis $(\mathbf{8 d}>\mathbf{8 f}>\mathbf{8 e})$.

After that, all these derivatives were further studied for their stimulating effect on tyrosinase. ${ }^{37}$ As shown in Fig. 7, only two compounds $(\mathbf{8 a}, \mathbf{8 0})$ showed a higher value than 8 -MOP. And it can be noticed that the $-\mathrm{Cl}$, and $-\mathrm{OCH}_{3}$ groups might be favorable to enhance the activity among these monosubstituted compounds, since the value of them were all over $110 \%(8 \mathbf{a}-\mathbf{8 c}$, 
<smiles></smiles>

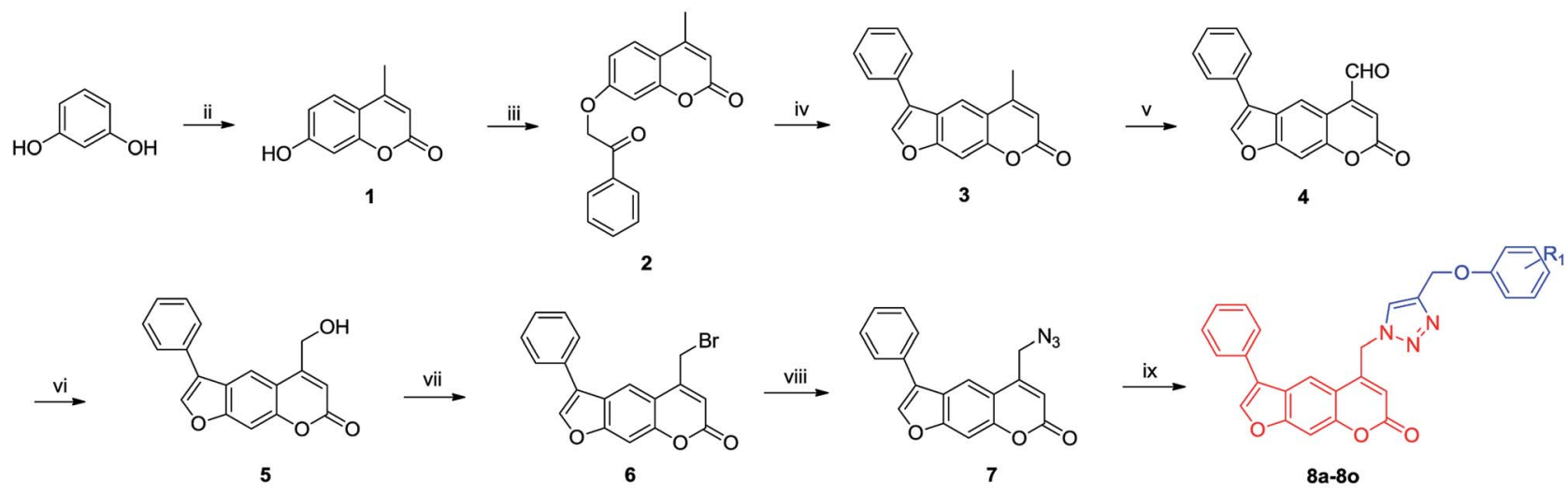

$$
\begin{array}{lllll}
\text { 8a: } \mathrm{R}_{1}=4-\mathrm{Cl} & \text { 8b: } \mathrm{R}_{1}=2-\mathrm{Cl} & \text { 8c: } \mathrm{R}_{1}=3-\mathrm{Cl} & \text { 8d: } \mathrm{R}_{1}=2.4-\mathrm{diCl} & \text { 8e: } \mathrm{R}_{1}=3,5-\mathrm{diCl} \\
\text { 8f: } \mathrm{R}_{1}=3,4-\mathrm{diCl} & \text { 8g: } \mathrm{R}_{1}=4-\mathrm{F} & \text { 8h: } \mathrm{R}_{1}=2-\mathrm{F} & \text { 8i: } \mathrm{R}_{1}=3,5-\mathrm{diF} & \text { 8j: } \mathrm{R}_{1}=4-\mathrm{Br} \\
\text { 8k: } \mathrm{R}_{1}=\mathrm{H} & \text { 8I: } \mathrm{R}_{1}=2-\mathrm{CH}_{3} & \text { 8m: } \mathrm{R}_{1}=4-\mathrm{CH}_{3} & \text { 8n: } \mathrm{R}_{1}=2-\mathrm{OCH}_{3} & \text { 8o: } \mathrm{R}_{1}=4-\mathrm{OCH}_{3}
\end{array}
$$

Scheme 1 Synthesis of furocoumarin derivatives containing 1,2,3-triazole (8a-8o). Reagents and conditions: (i) $\mathrm{DMF}, \mathrm{K}_{2} \mathrm{CO} \mathrm{O}_{3}, 70{ }^{\circ} \mathrm{C}$ (ii) ethyl acetoacetate, $\mathrm{H}_{2} \mathrm{SO}_{4}, 60{ }^{\circ} \mathrm{C}$ (iii) 2-bromoacetophenone, $\mathrm{K}_{2} \mathrm{CO}_{3}$, acetone, reflux (iv) $4 \% \mathrm{KOH}$ ethanolic solution, reflux (v) SeO 2 , xylene, reflux (vi): $\mathrm{NaBH}_{4}$, methanol, rt (vii): $\mathrm{PBr}_{3}, \mathrm{THF}, 0{ }^{\circ} \mathrm{C}$-rt (viii): $\mathrm{NaN}_{3}, \mathrm{CH}_{3} \mathrm{CN}$, reflux (ix) a-o, $\mathrm{CuSO}_{4} \cdot 5 \mathrm{H}_{2} \mathrm{O}, \mathrm{Cu}, t-\mathrm{BuOH}: \mathrm{H}_{2} \mathrm{O}=1: 3,80{ }^{\circ} \mathrm{C}$.

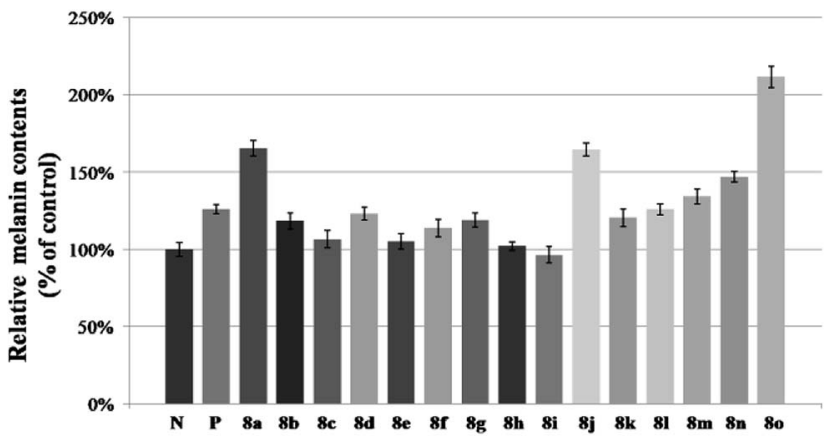

Fig. 6 Stimulation of melanin content of B16 cells by $8 a-80$. N means negative control; $\mathrm{P}$ means positive control (8-MOP); the B16 cells was treated with $50 \mu \mathrm{M}$ different furocoumarin derivatives for $48 \mathrm{~h}$. After that, melanin content was measured directly. Values are expressed as the mean \pm SD of three separate experiments, $P<0.05$.

8n-8o $>110 \%)$. Changing the position of $-\mathrm{Cl}$ on benzene ring weakened stimulatory efficiency $(\mathbf{8 a}>\mathbf{8 b}$ or $\mathbf{8 c})$, indicating that the presence of a substituent in the para-position may be beneficial for the enzyme activation, and it was also applicable for the $\mathrm{OCH}_{3}$ group $(\mathbf{8 0}>\mathbf{8 n})$. Nevertheless, dihalide derivatives possessed a lower activity than mono- ones. Additionally, the effect of most potential $\mathbf{8 a}, \mathbf{8 n}$, on both melanin synthesis and tyrosinase activity, were positively in a concentration dependent manner as depicted in Fig. 8.

\section{Experimental}

\subsection{Chemistry}

Reagents and solvents were purchased from Sigma, and used without further purification. Thin-layer chromatography (TLC)

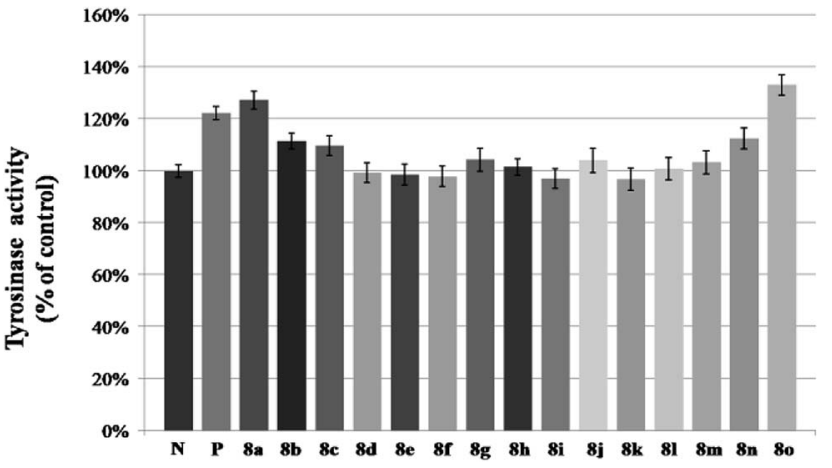

Fig. 7 Stimulation of tyrosinase activity of $\mathrm{B} 16$ cells by $8 \mathrm{a}-80$. $\mathrm{N}$ means negative control; $P$ means positive control (8-MOP). B16 cells was treated with $50 \mu \mathrm{M}$ different furocoumarin derivatives for $48 \mathrm{~h}$. After that, tyrosinase activity was measured directly. The data are the mean \pm SD of three experiments, $P<0.05$.

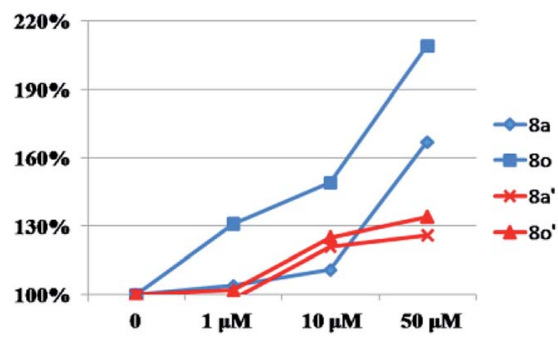

Fig. 8 The concentration dependent manner of $8 a, 80$ on melanin synthesis and tyrosinase activity. " $\bullet$ ", " $\mathbf{\square}$ " and " $\times$ ", " $\mathbf{\Delta}$ " means the effect of $8 \mathrm{a}, 80$ on melanin synthesis (in blue) and tyrosinase activity (in red) separately at different concentration in B16 cells. 
was carried out on glass plates coated with silica gel (Qingdao Haiyang Chemical Co., G60F-254) and visualized by UV light $(254 \mathrm{~nm})$. The products were purified by column chromatography over silica gel (Qingdao Haiyang Chemical Co., 200-300 mesh). Melting points were determined on a Buchi B-540 apparatus and uncorrected. All the NMR spectra were recorded with a Varian $400 \mathrm{MHz} \mathrm{NMR}$ spectrometer in $\mathrm{CDCl}_{3}$ or acetone- $d_{6}$, using TMS as an internal standard. High-resolution mass spectra (HRMS) were recorded on AB SCIEX QSTAR Elite quadrupole time-of-flight mass spectrometry. The IR data were recorded on a Thermo Fisher Scientific Nicolet 6700 FT-IR infrared spectrometer $(\mathrm{KBr})$.

3.1.1 General procedure of preparation of alkyne a-o. To substituted phenol $(3.50 \mathrm{mmol})$ and potassium carbonate (10.5 mmol, $1.45 \mathrm{~g}$ ) in DMF was added 3-bromopropyne (4.20 mmol, $500 \mathrm{mg}$ ) and stirred at $70{ }^{\circ} \mathrm{C}$ overnight. Then the mixture was quenched with water, extraction was with DCM $(20 \mathrm{~mL} \times 3)$ and the combined organic layer was washed by saturated sodium chloride solution for three times, dried by anhydrous $\mathrm{Na}_{2} \mathrm{SO}_{4}$ and concentrated under reduced pressure to give a oil or solid, which was purified by silica gel chromatography.

a: ${ }^{1} \mathrm{H}$ NMR $\left(400 \mathrm{MHz}, \mathrm{CDCl}_{3}\right) \delta 7.26(\mathrm{~d}, J=8.9 \mathrm{~Hz}, 2 \mathrm{H}), 6.92$ $(\mathrm{d}, J=8.9 \mathrm{~Hz}, 2 \mathrm{H}), 4.67(\mathrm{~d}, J=2.4 \mathrm{~Hz}, 2 \mathrm{H}), 2.52(\mathrm{t}, J=2.4 \mathrm{~Hz}$, $1 \mathrm{H})$.

d: ${ }^{1} \mathrm{H}$ NMR $\left(400 \mathrm{MHz}, \mathrm{CDCl}_{3}\right) \delta 7.38(\mathrm{~d}, J=2.5 \mathrm{~Hz}, 1 \mathrm{H}), 7.20$ $(\mathrm{dd}, J=8.8,2.5 \mathrm{~Hz}, 1 \mathrm{H}), 7.02(\mathrm{~d}, J=8.8 \mathrm{~Hz}, 1 \mathrm{H}), 4.76(\mathrm{~d}, J=$ $2.4 \mathrm{~Hz}, 2 \mathrm{H}), 2.55$ (t, $J=2.3 \mathrm{~Hz}, 1 \mathrm{H})$.

e: ${ }^{1} \mathrm{H} \mathrm{NMR}\left(400 \mathrm{MHz}, \mathrm{CDCl}_{3}\right) \delta 7.01(\mathrm{t}, J=1.7 \mathrm{~Hz}, 1 \mathrm{H}), 6.88(\mathrm{~d}$, $J=1.7 \mathrm{~Hz}, 2 \mathrm{H}), 4.67$ (d, $J=2.4 \mathrm{~Hz}, 2 \mathrm{H}), 2.57$ (t, $J=2.4 \mathrm{~Hz}, 1 \mathrm{H})$.

k: ${ }^{1} \mathrm{H}$ NMR (400 MHz, $\left.\mathrm{CDCl}_{3}\right) \delta$ 7.37-7.29 (m, 2H), 7.05-6.97 $(\mathrm{m}, 3 \mathrm{H}), 4.71(\mathrm{~d}, J=2.4 \mathrm{~Hz}, 2 \mathrm{H}), 2.53(\mathrm{t}, J=2.4 \mathrm{~Hz}, 1 \mathrm{H})$.

l: ${ }^{1} \mathrm{H}$ NMR (400 MHz, $\mathrm{CDCl}_{3}$ ) $\delta$ 7.26-7.21, (m, 2H), 7.06-6.95 $(\mathrm{m}, 2 \mathrm{H}), 4.76(\mathrm{~d}, J=2.4 \mathrm{~Hz}, 2 \mathrm{H}), 2.56(\mathrm{t}, J=2.4 \mathrm{~Hz}, 1 \mathrm{H}), 2.34(\mathrm{~s}$, $3 \mathrm{H})$.

o: ${ }^{1} \mathrm{H}$ NMR $\left(400 \mathrm{MHz}, \mathrm{CDCl}_{3}\right) \delta 6.93(\mathrm{~d}, J=9.1 \mathrm{~Hz}, 2 \mathrm{H}), 6.85$ $(\mathrm{d}, J=9.1 \mathrm{~Hz}, 2 \mathrm{H}), 4.64(\mathrm{~d}, J=2.4 \mathrm{~Hz}, 2 \mathrm{H}), 3.77(\mathrm{~s}, 3 \mathrm{H}), 2.51(\mathrm{t}, J$ $=2.3 \mathrm{~Hz}, 1 \mathrm{H})$.

3.1.2 Preparation of 7-hydroxy-4-methyl-2H-chromen-2one (1). To an ice-cold solution of resorcinol $(2.0 \mathrm{~g}, 18.2 \mathrm{~mol})$ in dioxane, conc. $\mathrm{H}_{2} \mathrm{SO}_{4}(0.5 \mathrm{~mL})$ was added dropwise under $20{ }^{\circ} \mathrm{C}$. After that, ethyl acetoacetate $(2.8 \mathrm{~g}, 21.8 \mathrm{mmol})$ was added, and the mixture was heated to $60^{\circ} \mathrm{C}$ for $4 \mathrm{~h}$. Then, the mixture was poured into cold water, and the precipitate was filtered and dried under reduced pressure. The resulting mixture was recrystallized from methanol to give $\mathbf{1}$ as white needle crystals. Yield $92 \%, \mathrm{mp} 202-204{ }^{\circ} \mathrm{C}$.

3.1.3 Preparation of 4-methyl-7-(2-oxo-2-phenylethoxy)-2Hchromen-2-one (2). A mixture of $1(0.88 \mathrm{~g}, 5.0 \mathrm{mmol})$ with 2bromoacetophenone (1.49 g, $7.5 \mathrm{mmol}$ ) and anhydrous $\mathrm{K}_{2} \mathrm{CO}_{3}$ $(1.4 \mathrm{~g}, 10 \mathrm{mmol})$ in acetone $(50 \mathrm{~mL})$ was refluxed under stirring for $4 \mathrm{~h}$. After cooling, the reaction mixture was filtered, and the filtrate was evaporated under reduced pressure. The obtained residue was purified by silica gel chromatography with petroleum ether/ethyl acetate to give intermediate 2. Yield $90 \%$, white solid, mp $162-164{ }^{\circ} \mathrm{C} ;{ }^{1} \mathrm{H}$ NMR (400 $\left.\mathrm{MHz}, \mathrm{CDCl}_{3}\right) \delta 7.98$ (dd, $J=8.2,1.0 \mathrm{~Hz}, 2 \mathrm{H}), 7.64$ (t, $J=7.4 \mathrm{~Hz}, 1 \mathrm{H}), 7.51$ (m, 7.55-
7.48, 3H), $6.94(\mathrm{dd}, J=8.8,2.6 \mathrm{~Hz}, 1 \mathrm{H}), 6.79(\mathrm{~d}, J=2.5 \mathrm{~Hz}, 1 \mathrm{H})$, $6.13(\mathrm{~d}, J=1.1 \mathrm{~Hz}, 1 \mathrm{H}), 5.38(\mathrm{~s}, 2 \mathrm{H}), 2.38(\mathrm{~d}, J=1.1 \mathrm{~Hz}, 3 \mathrm{H})$.

3.1.4 Preparation of 5-methyl-3-phenyl-7 $\mathrm{H}$-furo[3,2-g] chromen-7-one (3). To an ethanolic solution (100 mL) of intermediate $2(2.94 \mathrm{~g}, 10 \mathrm{mmol})$ was added a $4 \%$ ethanol potassium hydroxide solution $(20 \mathrm{~mL})$ and the mixture was refluxed for $4 \mathrm{~h}$. After cooling, the solution was acidified with $1 \mathrm{M}$ hydrochloric acid and extracted with ethyl acetate three times. The organic phase was dried over night and evaporated under reduced pressure. The resulting residue was purified by silica gel chromatography with petroleum ether/ethyl acetate to give compound 3. Yield 95\%, white solid, mp 171-173 ${ }^{\circ} \mathrm{C} ;{ }^{1} \mathrm{H}$ NMR $\left(400 \mathrm{MHz}, \mathrm{CDCl}_{3}\right) \delta 7.98(\mathrm{~s}, 1 \mathrm{H}), 7.83(\mathrm{~s}, 1 \mathrm{H}), 7.64(\mathrm{dd}, J=8.2$, $1.1 \mathrm{~Hz}, 2 \mathrm{H}), 7.50-7.56(\mathrm{~m}, 3 \mathrm{H}), 7.44(\mathrm{td}, J=7.4,1.1 \mathrm{~Hz}, 1 \mathrm{H}), 6.29$ (s, 1H), $2.52(\mathrm{~s}, 3 \mathrm{H})$.

3.1.5 Preparation of 7-oxo-3-phenyl-7H-furo[3,2-g] chromene-5-carbaldehyde (4). Powdered $\mathrm{SeO}_{2}$ (3.33 g, 30 $\mathrm{mmol})$ was added to a solution of $3(5.52 \mathrm{~g}, 20 \mathrm{mmol})$ in $20 \mathrm{~mL}$ of hot dry xylene and the mixture were refluxed for $24 \mathrm{~h}$ with vigorous stirring under the nitrogen. The reaction mixture was filtered to remove black Se, and the deep orange filtrate was allowed to stand overnight. Almost pure crystals of 4 could be separated from the solution. Yield $63 \%$, yellow solid, mp 148$150{ }^{\circ} \mathrm{C} ;{ }^{1} \mathrm{H}$ NMR $\left(400 \mathrm{MHz}, \mathrm{CDCl}_{3}\right) \delta 10.14(\mathrm{~s}, 1 \mathrm{H}), 9.10(\mathrm{~s}, 1 \mathrm{H})$, 7.87 (s, 1H), 7.66 (d, $J=7.4 \mathrm{~Hz}, 2 \mathrm{H}), 7.59-7.49(\mathrm{~m}, 3 \mathrm{H}), 7.44$ (t, $J$ $=7.2 \mathrm{~Hz}, 1 \mathrm{H}), 6.86(\mathrm{~s}, 1 \mathrm{H})$.

3.1.6 Preparation of 5-(hydroxymethyl)-3-phenyl-7 $\mathrm{H}$-furo [3,2-g]chromen-7-one (5). Compound 4 (5.80 g, $20 \mathrm{mmol})$ was dissolved in ethanol $(130 \mathrm{~mL})$, sodium borohydride $(380 \mathrm{mg}$, $10.0 \mathrm{mmol}$ ) was added, and the solution was stirred for $2 \mathrm{~h}$ at room temperature. Thereafter the suspension was carefully hydrolyzed with $1 \mathrm{M} \mathrm{HCl}(20 \mathrm{~mL})$, diluted with $\mathrm{H}_{2} \mathrm{O}$ and extracted three times with DCM. The organic phase was washed with brine, dried over $\mathrm{Na}_{2} \mathrm{SO}_{4}$ and evaporated under reduced pressure. The residue was purified by flash chromatography on silica gel to afford alcohol 5. Yield 76\%, white solid, mp 99$100{ }^{\circ} \mathrm{C} ;{ }^{1} \mathrm{H}$ NMR $\left(400 \mathrm{MHz}, \mathrm{CDCl}_{3}\right) \delta 7.85(\mathrm{~s}, 1 \mathrm{H}), 7.79(\mathrm{~s}, 1 \mathrm{H})$, $7.59(\mathrm{~d}, J=7.3 \mathrm{~Hz}, 2 \mathrm{H}), 7.55-7.47(\mathrm{~m}, 2 \mathrm{H}), 7.46-7.38(\mathrm{~m}, 2 \mathrm{H})$, $6.62(\mathrm{~s}, 1 \mathrm{H}), 4.97(\mathrm{~s}, 2 \mathrm{H})$.

3.1.7. Preparation of 5-(bromomethyl)-3-phenyl-7 $\mathrm{H}$-furo [3,2-g] chromen-7-one (6). A mixture of 5 (2.92 g, $10 \mathrm{mmol})$ in anhydrous THF $\left(25 \mathrm{~mL}\right.$ ) was cooled to $0{ }^{\circ} \mathrm{C}$, a solution of $\mathrm{PBr}_{3}$ $(0.95 \mathrm{~mL}, 10 \mathrm{mmol})$ in THF $(2 \mathrm{~mL})$ was added dropwise in icebath and stirred at room temperature. After the raw material consumed, the mixture was neutralized with $\mathrm{NaHCO}_{3}$ and extracted with DCM two times. The organic phase was evaporated under reduced pressure and purified by silica gel chromatography with petroleum ether/ethyl acetate to give 6 . Yield 88\%, light yellow solid, mp $175-177{ }^{\circ} \mathrm{C} ;{ }^{1} \mathrm{H}$ NMR $(400 \mathrm{MHz}$, $\left.\mathrm{CDCl}_{3}\right) \delta 8.13(\mathrm{~s}, 1 \mathrm{H}), 7.86(\mathrm{~s}, 1 \mathrm{H}), 7.68-7.61(\mathrm{~m}, 3 \mathrm{H}), 7.58-7.53$ $(\mathrm{m}, 3 \mathrm{H}), 6.53(\mathrm{~s}, 1 \mathrm{H}), 4.57(\mathrm{~s}, 2 \mathrm{H})$.

3.1.8 Preparation of 5-(azidomethyl)-3-phenyl-7 $\mathrm{H}$-furo[3,2g]chromen-7-one (7). To 6 (3.55 g, $10 \mathrm{mmol})$ in acetonitrile was added sodium azide $(0.96 \mathrm{~g}, 14.8 \mathrm{mmol})$ and stirred at reflux for $12 \mathrm{~h}$. The resulting mixture was evaporated under reduced pressure and purified by silica gel chromatography with petroleum ether/ethyl acetate to give compound 7. Yield 81\%, yellow 
solid, mp $188-190{ }^{\circ} \mathrm{C} ;{ }^{1} \mathrm{H}$ NMR $\left(400 \mathrm{MHz}, \mathrm{CDCl}_{3}\right) \delta 7.91(\mathrm{~s}, 1 \mathrm{H})$, $7.85(\mathrm{~s}, 1 \mathrm{H}), 7.62(\mathrm{~d}, J=7.3,2 \mathrm{H}), 7.58-7.53(\mathrm{~m}, 3 \mathrm{H}), 7.45(\mathrm{t}, J=$ 7.4, 1H), $6.53(\mathrm{~s}, 1 \mathrm{H}), 4.64(\mathrm{~s}, 2 \mathrm{H})$.

3.1.9 General procedure of preparation of 8a-8o. To compound 7 (0.32 g, $1.0 \mathrm{mmol})$ and alkyne a-o $(1.2 \mathrm{mmol})$ in $20 \mathrm{~mL}$ mixture $\left(\mathrm{v}_{\text {tert }}\right.$-butanol $\left./ \mathrm{v}_{\mathrm{H}_{2} \mathrm{O}}=3: 1\right)$ were added copper sulfate pentahydrate $(0.44 \mathrm{mg}, 1.75 \mathrm{mmol})$ and copper $(0.06 \mathrm{~g}$, $1.0 \mathrm{mmol}$ ). The reaction was stirred at $80^{\circ} \mathrm{C}$ overnight. Then the suspension was extracted with DCM $(10 \mathrm{~mL} \times 2)$, the combined organic layer was dried over anhydrous $\mathrm{Na}_{2} \mathrm{SO}_{4}$ and concentrated under reduced pressure to give a residue, which was purified by silica gel chromatography to afford final compounds 8a-8o.

3.1.9.1 5-((4-((4-Chlorophenoxy)methyl)-1H-1,2,3-triazol-1-yl) methyl)-3-phenyl-7H-furo[3,2-g]chromen-7-one (8a). Yield 84\%, light yellow solid, mp 180-182 ${ }^{\circ} \mathrm{C} ;{ }^{1} \mathrm{H}$ NMR (400 $\mathrm{MHz}, \mathrm{CDCl}_{3}$ ) $\delta 8.04(\mathrm{~s}, 1 \mathrm{H}), 7.86(\mathrm{~s}, 1 \mathrm{H}), 7.70(\mathrm{~s}, 1 \mathrm{H}), 7.58-7.53(\mathrm{~m}, 5 \mathrm{H}), 7.48-$ $7.41(\mathrm{~m}, 1 \mathrm{H}), 7.21(\mathrm{~d}, J=9.0 \mathrm{~Hz}, 2 \mathrm{H}), 6.88(\mathrm{~d}, J=9.0 \mathrm{~Hz}, 2 \mathrm{H})$, $6.05(\mathrm{~s}, 1 \mathrm{H}), 5.80(\mathrm{~s}, 2 \mathrm{H}), 5.21(\mathrm{~s}, 2 \mathrm{H}) .{ }^{13} \mathrm{C} \mathrm{NMR}\left(101 \mathrm{MHz}, \mathrm{CDCl}_{3}\right)$ $\delta$ 160.06, 157.52, 156.70, 152.07, 148.18, 143.47, 130.56, 129.60, 129.54, 128.48, 127.65, 124.70, 123.40, 122.48, 116.24, 115.20, 114.02, 113.62, 101.06, 62.33, 50.95; IR (KBr) $\nu: 2925,1732,1635$, 1576, 1489, 1240, 1151, $823 \mathrm{~cm}^{-1}$; HRMS (ESI) calcd for $\mathrm{C}_{27^{-}}$ $\mathrm{H}_{19} \mathrm{ClN}_{3} \mathrm{O}_{4}[\mathrm{M}+\mathrm{H}]^{+}$484.0986, found 484.0993.

3.1.9.2 5-((4-((2-Chlorophenoxy)methyl)-1H-1,2,3-triazol-1-yl) methyl)-3-phenyl-7H-furo[3,2-g]chromen-7-one (8b). Yield 86\%, light yellow solid, mp $198-201{ }^{\circ} \mathrm{C} ;{ }^{1} \mathrm{H}$ NMR (400 $\mathrm{MHz}, \mathrm{CDCl}_{3}$ ) $\delta 8.04(\mathrm{~s}, 1 \mathrm{H}), 7.86(\mathrm{~s}, 1 \mathrm{H}), 7.77(\mathrm{~s}, 1 \mathrm{H}), 7.59-7.50(\mathrm{~m}, 5 \mathrm{H}), 7.48-$ $7.40(\mathrm{~m}, 1 \mathrm{H}), 7.33(\mathrm{~d}, J=8.0 \mathrm{~Hz}, 1 \mathrm{H}), 7.22-7.15(\mathrm{~m}, 1 \mathrm{H}), 7.06(\mathrm{~d}, J$ $=8.2 \mathrm{~Hz}, 1 \mathrm{H}), 6.94-6.87(\mathrm{~m}, 1 \mathrm{H}), 6.02(\mathrm{~s}, 1 \mathrm{H}), 5.81(\mathrm{~s}, 2 \mathrm{H}), 5.33$ (s, 2H). $\left.{ }^{13} \mathrm{C} \mathrm{NMR} \mathrm{(101} \mathrm{MHz,} \mathrm{CDCl}_{3}\right) \delta 160.05,157.51,153.66$, 152.08, 148.24, 145.51, 143.42, 132.60, 131.02, 130.57, 129.53, 128.95, 128.46, 127.98, 127.67, 124.68, 123.49, 122.51, 115.16, 114.57, 113.92, 101.05, 63.52, 50.90; IR (KBr) $\nu: 2926,1719,1634$, 1484, 1273, 1152, 1067, $754 \mathrm{~cm}^{-1}$; HRMS (ESI) calcd for $\mathrm{C}_{27^{-}}$ $\mathrm{H}_{19} \mathrm{ClN}_{3} \mathrm{O}_{4}[\mathrm{M}+\mathrm{H}]^{+}$484.0986, found 484.0977.

3.1.9.3 5-((4-((3-Chlorophenoxy)methyl)-1H-1,2,3-triazol-1-yl) methyl)-3-phenyl-7H-furo[3,2-g]chromen-7-one (8c). Yield 82\%, light yellow solid, mp 110-111 ${ }^{\circ} \mathrm{C} ;{ }^{1} \mathrm{H}$ NMR (400 $\mathrm{MHz}, \mathrm{CDCl}_{3}$ ) $\delta 8.04(\mathrm{~s}, 1 \mathrm{H}), 7.86(\mathrm{~s}, 1 \mathrm{H}), 7.71(\mathrm{~s}, 1 \mathrm{H}), 7.59-7.52(\mathrm{~m}, 5 \mathrm{H}), 7.48-$ $7.41(\mathrm{~m}, 1 \mathrm{H}), 7.22-7.15(\mathrm{~m}, 1 \mathrm{H}), 6.99-6.92(\mathrm{~m}, 2 \mathrm{H}), 6.85(\mathrm{~d}, J=$ $8.6 \mathrm{~Hz}, 1 \mathrm{H}), 6.06(\mathrm{~s}, 1 \mathrm{H}), 5.81(\mathrm{~s}, 2 \mathrm{H}), 5.22(\mathrm{~s}, 2 \mathrm{H}) .{ }^{13} \mathrm{C}$ NMR $(101$ $\left.\mathrm{MHz}, \mathrm{CDCl}_{3}\right) \delta 160.06,158.84,157.53,152.09,148.17,143.45$, 135.14, 131.06, 130.56, 130.50, 129.54, 128.48, 127.67, 123.36, 121.83, 115.56, 115.21, 114.04, 113.64, 113.22, 110.17, 108.07, 101.08, 62.27, 50.96; IR (KBr) $\nu$ : 2924, 1733, 1635, 1457, 1274, $1152 \mathrm{~cm}^{-1}$; HRMS (ESI) calcd for $\mathrm{C}_{27} \mathrm{H}_{19} \mathrm{ClN}_{3} \mathrm{O}_{4}[\mathrm{M}+\mathrm{H}]^{+}$ 484.0986, found 484.1004.

3.1.9.4 5-((4-((2,4-Dichlorophenoxy)methyl)-1H-1,2,3-triazol1-yl)methyl)-3-phenyl-7H-furo[3,2-g]chromen-7-one (8d). Yield $86 \%$, light yellow solid, mp $121-123{ }^{\circ} \mathrm{C} ;{ }^{1} \mathrm{H}$ NMR $(400 \mathrm{MHz}$, $\left.\mathrm{CDCl}_{3}\right) \delta 8.03(\mathrm{~s}, 1 \mathrm{H}), 7.86(\mathrm{~s}, 1 \mathrm{H}), 7.75(\mathrm{~s}, 1 \mathrm{H}), 7.59-7.50(\mathrm{~m}, 5 \mathrm{H})$, $7.48-7.41(\mathrm{~m}, 1 \mathrm{H}), 7.32$ (d, $J=2.4 \mathrm{~Hz}, 1 \mathrm{H}), 7.14(\mathrm{dd}, J=8.8$, $2.5 \mathrm{~Hz}, 1 \mathrm{H}), 7.00$ (d, $J=8.8 \mathrm{~Hz}, 1 \mathrm{H}), 6.03(\mathrm{~s}, 1 \mathrm{H}), 5.81(\mathrm{~s}, 2 \mathrm{H})$, $5.30(\mathrm{~s}, 2 \mathrm{H}) .{ }^{13} \mathrm{C} \mathrm{NMR}\left(101 \mathrm{MHz}, \mathrm{CDCl}_{3}\right) \delta 161.13,157.53$, 155.69, 152.48, 148.16, 143.47, 142.31, 131.06, 130.29, 129.53, 128.99, 128.47, 127.87, 127.65, 125.78, 124.70, 123.58, 115.35,
115.14, 113.98, 110.98, 101.09, 63.68, 50.95; IR (KBr) $\nu: 2925$, 1733, 1635, 1576, 1473, $1271 \mathrm{~cm}^{-1}$; HRMS (ESI) calcd for $\mathrm{C}_{27^{-}}$ $\mathrm{H}_{18} \mathrm{Cl}_{2} \mathrm{~N}_{3} \mathrm{O}_{4}[\mathrm{M}+\mathrm{H}]^{+}$518.0669, found 518.0680.

3.1.9.5 5-((4-((3,5-Dichlorophenoxy)methyl)-1H-1,2,3-triazol1-yl)methyl)-3-phenyl-7H-furo[3,2-g]chromen-7-one (8e). Yield $88 \%$, light yellow solid, mp $223-224{ }^{\circ} \mathrm{C} ;{ }^{1} \mathrm{H}$ NMR $(400 \mathrm{MHz}$, $\left.\mathrm{CDCl}_{3}\right) \delta 8.04(\mathrm{~s}, 1 \mathrm{H}), 7.86(\mathrm{~s}, 1 \mathrm{H}), 7.70(\mathrm{~s}, 1 \mathrm{H}), 7.57-7.51(\mathrm{~m}, 5 \mathrm{H})$, $7.48-7.41(\mathrm{~m}, 1 \mathrm{H}), 6.97(\mathrm{t}, J=1.8 \mathrm{~Hz}, 1 \mathrm{H}), 6.87(\mathrm{~d}, J=1.7 \mathrm{~Hz}$, 2H), 6.07 (s, 1H), $5.82(\mathrm{~s}, 2 \mathrm{H}), 5.20(\mathrm{~s}, 2 \mathrm{H}) .{ }^{13} \mathrm{C}$ NMR $(101 \mathrm{MHz}$, $\left.\mathrm{CDCl}_{3}\right) \delta 160.04,157.32,156.52,152.79,148.11,143.48,131.06$, 129.54, 129.41, 128.99, 128.49, 127.66, 124.73, 123.47, 121.98, 115.20, 114.06, 113.77, 109.69, 101.10, 62.44, 50.98; IR (KBr) $\nu$ : 2926, 1732, 1634, 1571, 1457, 1273, 1150, $1074 \mathrm{~cm}^{-1}$; HRMS (ESI) calcd for $\mathrm{C}_{27} \mathrm{H}_{18} \mathrm{Cl}_{2} \mathrm{~N}_{3} \mathrm{O}_{4}[\mathrm{M}+\mathrm{H}]^{+} 518.0669$, found 518.0651 .

3.1.9.6 5-((4-((3,4-Dichlorophenoxy)methyl)-1H-1,2,3-triazol1-yl)methyl)-3-phenyl-7H-furo[3,2-g]chromen-7-one (8f). Yield $80 \%$, light yellow solid, mp $159-161{ }^{\circ} \mathrm{C} ;{ }^{1} \mathrm{H}$ NMR $(400 \mathrm{MHz}$, $\left.\mathrm{CDCl}_{3}\right) \delta 8.04(\mathrm{~s}, 1 \mathrm{H}), 7.86(\mathrm{~s}, 1 \mathrm{H}), 7.71(\mathrm{~s}, 1 \mathrm{H}), 7.59-7.52(\mathrm{~m}, 5 \mathrm{H})$, $7.49-7.41(\mathrm{~m}, 1 \mathrm{H}), 7.30(\mathrm{~d}, J=8.9 \mathrm{~Hz}, 1 \mathrm{H}), 7.07$ (d, $J=2.9 \mathrm{~Hz}$, $1 \mathrm{H}), 6.82(\mathrm{dd}, J=9.0,2.9 \mathrm{~Hz}, 1 \mathrm{H}), 6.06(\mathrm{~s}, 1 \mathrm{H}), 5.81(\mathrm{~s}, 2 \mathrm{H}), 5.20$ (s, 2H). $\left.{ }^{13} \mathrm{C} \mathrm{NMR} \mathrm{(101} \mathrm{MHz,} \mathrm{CDCl}_{3}\right) \delta 160.05,157.54,157.10$, $156.31,152.08,148.13,143.49,130.95,129.53$, 128.48, 127.65, 124.72 , 123.47, 122.49, 117.05, 115.19, 114.77, 114.05, 113.60, 110.15, 101.09, 62.46, 50.98; IR (KBr) $\nu$ : 2924, 1733, 1653, 1576, $1473,1274,1048 \mathrm{~cm}^{-1}$; HRMS (ESI) calcd for $\mathrm{C}_{27} \mathrm{H}_{18} \mathrm{Cl}_{2} \mathrm{~N}_{3} \mathrm{O}_{4}[\mathrm{M}$ $+\mathrm{H}]^{+}$518.0669, found 518.0682.

3.1.9.7 5-((4-((4-Fluorophenoxy)methyl)-1H-1,2,3-triazol-1-yl) methyl)-3-phenyl-7H-furo[3,2-g]chromen-7-one (8g). Yield 82\%, light yellow solid, mp $184-185{ }^{\circ} \mathrm{C} ;{ }^{1} \mathrm{H}$ NMR (400 MHz, $\mathrm{CDCl}_{3}$ ) $\delta 8.04(\mathrm{~s}, 1 \mathrm{H}), 7.86(\mathrm{~s}, 1 \mathrm{H}), 7.71(\mathrm{~s}, 1 \mathrm{H}), 7.59-7.50(\mathrm{~m}, 6 \mathrm{H}), 7.48-$ 7.41(m, 1H), 6.99-6.85 (m, 4H), $6.04(\mathrm{~s}, 1 \mathrm{H}), 5.80(\mathrm{~s}, 2 \mathrm{H}), 5.19(\mathrm{~s}$, $2 \mathrm{H}) .{ }^{13} \mathrm{C} \mathrm{NMR}\left(101 \mathrm{MHz}, \mathrm{CDCl}_{3}\right) \delta 160.06,157.50,156.54$, $154.20,152.05,148.24,143.45,131.02$, 129.53, 128.93, 128.46, $127.65,124.67,123.40,122.48,116.21,115.98,115.20,113.95$, 113.63, 101.03, 62.71, 50.90; IR (KBr) $\nu$ : 2926, 1732, 1634, 1576, 1506, 1389, 1202, 1152, $1040 \mathrm{~cm}^{-1}$; HRMS (ESI) calcd for $\mathrm{C}_{27} \mathrm{H}_{19} \mathrm{FN}_{3} \mathrm{O}_{4}[\mathrm{M}+\mathrm{H}]^{+}$468.1354, found 468.1367.

3.1.9.8 5-((4-((2-Fluorophenoxy)methyl)-1H-1,2,3-triazol-1-yl) methyl)-3-phenyl-7H-furo[3,2-g]chromen-7-one (8h). Yield 85\%, light yellow solid, mp 166-167 ${ }^{\circ} \mathrm{C} ;{ }^{1} \mathrm{H}$ NMR (400 MHz, $\mathrm{CDCl}_{3}$ ) $\delta 8.03(\mathrm{~s}, 1 \mathrm{H}), 7.85(\mathrm{~s}, 1 \mathrm{H}), 7.71(\mathrm{~s}, 1 \mathrm{H}), 7.61-7.49(\mathrm{~m}, 5 \mathrm{H}), 7.47-$ $7.40(\mathrm{~m}, 1 \mathrm{H}), 7.12-6.96(\mathrm{~m}, 3 \mathrm{H}), 6.96-6.85(\mathrm{~m}, 1 \mathrm{H}), 6.01(\mathrm{~s}, 1 \mathrm{H})$, $5.80(\mathrm{~s}, 2 \mathrm{H}), 5.30(\mathrm{~s}, 2 \mathrm{H}) .{ }^{13} \mathrm{C} \mathrm{NMR}\left(101 \mathrm{MHz}, \mathrm{CDCl}_{3}\right) \delta 160.03$, $157.50,154.29,152.06,148.21,146.00,143.42$, 132.45, 131.05, 130.56, 129.52, 128.97, 128.45, 127.66, 124.58, 122.41, 116.46, 115.19, 113.94, 113.66, 101.03, 63.65, 50.94; IR (KBr) $\nu: 2925$, 1733, 1634, 1506, 1457, 1257, 1152, $1047 \mathrm{~cm}^{-1}$; HRMS (ESI) calcd for $\mathrm{C}_{27} \mathrm{H}_{19} \mathrm{FN}_{3} \mathrm{O}_{4}[\mathrm{M}+\mathrm{H}]^{+}$468.1354, found 468.1371.

3.1.9.9 5-((4-((3,5-Difluorophenoxy)methyl)-1H-1,2,3-triazol1-yl)methyl)-3-phenyl-7H-furo[3,2-g]chromen-7-one (8i). Yield 83\%, light yellow solid, mp 210-212 ${ }^{\circ} \mathrm{C} ;{ }^{1} \mathrm{H}$ NMR $(400 \mathrm{MHz}$, $\left.\mathrm{CDCl}_{3}\right) \delta 8.05(\mathrm{~s}, 1 \mathrm{H}), 7.86(\mathrm{~s}, 1 \mathrm{H}), 7.72(\mathrm{~s}, 1 \mathrm{H}), 7.59-7.52(\mathrm{~m}, 5 \mathrm{H})$, $7.47-7.43(\mathrm{~m}, 1 \mathrm{H}), 6.50(\mathrm{~d}, J=8.8 \mathrm{~Hz}, 2 \mathrm{H}), 6.43(\mathrm{t}, J=8.9 \mathrm{~Hz}$, 1H), 6.06 (s, 1H), 5.82 (s, 2H), $5.19(\mathrm{~s}, 2 \mathrm{H}) .{ }^{13} \mathrm{C}$ NMR (101 MHz, $\left.\mathrm{CDCl}_{3}\right) \delta 160.04,157.54,155.60,152.09,148.12,143.48,131.06$, 129.54, 128.99, 128.49, 127.66, 124.74, 123.02, 122.53, 115.20, 
114.05, 113.58, 109.19, 101.09, 62.49, 50.98; IR (KBr) $\nu: 2923$, 1732, 1599, 1465, 1275, 1152, 1042, $996 \mathrm{~cm}^{-1}$; HRMS (ESI) calcd for $\mathrm{C}_{27} \mathrm{H}_{18} \mathrm{~F}_{2} \mathrm{~N}_{3} \mathrm{O}_{4}[\mathrm{M}+\mathrm{H}]^{+}$486.1260, found 486.1248.

3.1.9.10 5-((4-((4-Bromophenoxy)methyl)-1H-1,2,3-triazol-1yl)methyl)-3-phenyl-7H-furo[3,2-g]chromen-7-one (8j). Yield 84\%, light yellow solid, mp $104-105{ }^{\circ} \mathrm{C} ;{ }^{1} \mathrm{H}$ NMR (400 $\mathrm{MHz}, \mathrm{CDCl}_{3}$ ) $\delta 8.04(\mathrm{~s}, 1 \mathrm{H}), 7.86(\mathrm{~s}, 1 \mathrm{H}), 7.71(\mathrm{~s}, 1 \mathrm{H}), 7.59-7.51(\mathrm{~m}, 5 \mathrm{H}), 7.48-$ $7.41(\mathrm{~m}, 1 \mathrm{H}), 7.35(\mathrm{~d}, J=8.9 \mathrm{~Hz}, 2 \mathrm{H}), 6.84(\mathrm{~d}, J=8.9 \mathrm{~Hz}, 2 \mathrm{H})$, $6.05(\mathrm{~s}, 1 \mathrm{H}), 5.80(\mathrm{~s}, 2 \mathrm{H}), 5.20(\mathrm{~s}, 2 \mathrm{H}) .{ }^{13} \mathrm{C} \mathrm{NMR}\left(101 \mathrm{MHz}, \mathrm{CDCl}_{3}\right)$ $\delta$ 160.06, 157.52, 157.21, 153.19, 152.07, 148.17, 143.47, 132.54, 129.54, 128.48, 127.65, 124.69, 123.41, 122.49, 116.75, 115.20, 114.03, 113.85, 113.62, 101.07, 62.25, 50.95; IR (KBr) $\nu: 2926$, 1733, 1635, 1576, 1489, 1457, 1276, $1150 \mathrm{~cm}^{-1}$; HRMS (ESI) calcd for $\mathrm{C}_{27} \mathrm{H}_{19} \mathrm{BrN}_{3} \mathrm{O}_{4}[\mathrm{M}+\mathrm{H}]^{+}$528.0553, found 528.0571 .

3.1.9.11 5-((4-(Phenoxymethyl)-1H-1,2,3-triazol-1-yl)methyl)3-phenyl-7H-furo[3,2-g]chromen-7-one (8k). Yield 85\%, light yellow solid, mp $152-154{ }^{\circ} \mathrm{C} ;{ }^{1} \mathrm{H}$ NMR $\left(400 \mathrm{MHz}, \mathrm{CDCl}_{3}\right) \delta 8.05$ (s, 1H), $7.86(\mathrm{~s}, 1 \mathrm{H}), 7.72(\mathrm{~s}, 1 \mathrm{H}), 7.61-7.50(\mathrm{~m}, 5 \mathrm{H}), 7.48-7.41$ (m, 1H), 7.30-7.24 (m, 2H), 7.00-6.92 (m, 3H), 6.05 (s, 1H), 5.80 $(\mathrm{s}, 2 \mathrm{H}), 5.24(\mathrm{~s}, 2 \mathrm{H}) .{ }^{13} \mathrm{C} \mathrm{NMR}\left(101 \mathrm{MHz}, \mathrm{CDCl}_{3}\right) \delta 160.07,158.12$, 157.51, 152.08, 148.24, 143.42, 130.57, 129.72, 129.53, 128.46, $127.67,124.68,123.32,122.52,121.59,115.23,114.91,114.00$, 113.67, 101.03, 62.09, 50.90; IR (KBr) $\nu$ : 2925, 1732, 1634, 1490, 1274, 1150, $1047 \mathrm{~cm}^{-1}$; HRMS (ESI) calcd for $\mathrm{C}_{27} \mathrm{H}_{20} \mathrm{~N}_{3} \mathrm{O}_{4}[\mathrm{M}+$ $\mathrm{H}]^{+}$450.1448, found 450.1433.

3.1.9.12 5-((4-((o-Tolyloxy)methyl)-1H-1,2,3-triazol-1-yl) methyl)3-phenyl-7H-furo[3,2-g]chromen-7-one (8l). Yield 89\%, light yellow solid, mp $160-161{ }^{\circ} \mathrm{C} ;{ }^{1} \mathrm{H}$ NMR (400 $\mathrm{MHz}, \mathrm{CDCl}_{3}$ ) $\delta 8.05(\mathrm{~s}, 1 \mathrm{H}), 7.86(\mathrm{~s}, 1 \mathrm{H}), 7.68(\mathrm{~s}, 1 \mathrm{H}), 7.61-7.50(\mathrm{~m}, 5 \mathrm{H}), 7.48-$ $7.41(\mathrm{~m}, 1 \mathrm{H}), 7.08-7.17(\mathrm{~m}, 2 \mathrm{H}), 6.96-6.83(\mathrm{~m}, 2 \mathrm{H}), 6.04(\mathrm{~s}, 1 \mathrm{H})$, $5.81(\mathrm{~s}, 2 \mathrm{H}), 5.25(\mathrm{~s}, 2 \mathrm{H}), 2.19(\mathrm{~s}, 3 \mathrm{H}) .{ }^{13} \mathrm{C} \mathrm{NMR}\left(101 \mathrm{MHz}, \mathrm{CDCl}_{3}\right)$ $\delta 160.09,157.51,156.28,152.08,148.31,143.39,131.02,130.57$, 129.53 , 128.46, 127.67, 127.01, 124.68, 122.52, 121.31, 115.19, 113.89, 113.69, 111.70, 101.07, 62.41, 50.92, 29.86; IR (KBr) $\nu$ : 2925, 1733, 1635, 1460, 1273, 1152, $1046 \mathrm{~cm}^{-1}$; HRMS (ESI) calcd for $\mathrm{C}_{28} \mathrm{H}_{22} \mathrm{~N}_{3} \mathrm{O}_{4}[\mathrm{M}+\mathrm{H}]^{+}$464.1605, found 464.1616.

3.1.9.13 5-((4- $((p-T o l y l o x y) m e t h y l)-1 H-1,2,3-$ triazol-1-yl $)$ methyl)-3-phenyl-7H-furo[3,2-g]chromen-7-one (8m). Yield 91\%, light yellow solid, mp 218-220 ${ }^{\circ} \mathrm{C} ;{ }^{1} \mathrm{H}$ NMR (400 $\mathrm{MHz}, \mathrm{CDCl}_{3}$ ) $\delta 8.04(\mathrm{~s}, 1 \mathrm{H}), 7.86(\mathrm{~s}, 1 \mathrm{H}), 7.72(\mathrm{~s}, 1 \mathrm{H}), 7.60-7.51(\mathrm{~m}, 5 \mathrm{H}), 7.48-$ $7.41(\mathrm{~m}, 1 \mathrm{H}), 7.06(\mathrm{~d}, J=8.1 \mathrm{~Hz}, 2 \mathrm{H}), 6.85(\mathrm{~d}, J=8.4 \mathrm{~Hz}, 2 \mathrm{H})$, $6.05(\mathrm{~s}, 1 \mathrm{H}), 5.79(\mathrm{~s}, 2 \mathrm{H}), 5.20(\mathrm{~s}, 2 \mathrm{H}), 2.27$ (s, 3H). ${ }^{13} \mathrm{C}$ NMR $(101$ $\left.\mathrm{MHz}, \mathrm{CDCl}_{3}\right) \delta 160.07,157.50,156.00,152.08,148.23,143.45$, $143.37,130.89,130.57,130.15,129.54,128.46,127.67,124.67$, 122.52, 115.28, 115.23, 114.81, 114.06, 113.99, 113.68, 101.05, 62.26, 50.98, 29.85; IR (KBr) $\nu: 2925,1733,1647,1508,1457$, 1388, 1228, 1151, $1050 \mathrm{~cm}^{-1}$; HRMS (ESI) calcd for $\mathrm{C}_{28} \mathrm{H}_{22} \mathrm{~N}_{3} \mathrm{O}_{4}[\mathrm{M}+\mathrm{H}]^{+}$464.1605, found 464.1589.

3.1.9.14 5-((4-((2-Methoxyphenoxy)methyl)-1H-1,2,3-triazol-1yl)methyl)-3-phenyl-7H-furo[3,2-g]chromen-7-one (8n). Yield 90\%, light yellow solid, mp $172-173{ }^{\circ} \mathrm{C} ;{ }^{1} \mathrm{H}$ NMR (600 $\mathrm{MHz}, \mathrm{CDCl}_{3}$ ) $\delta 8.04(\mathrm{~s}, 1 \mathrm{H}), 7.86(\mathrm{~s}, 1 \mathrm{H}), 7.71(\mathrm{~s}, 1 \mathrm{H}), 7.59-7.51(\mathrm{~m}, 5 \mathrm{H}), 7.48-$ $7.41(\mathrm{~m}, 1 \mathrm{H}), 6.99(\mathrm{~d}, J=8.0 \mathrm{~Hz}, 1 \mathrm{H}), 6.95-6.90(\mathrm{~m}, 1 \mathrm{H}), 6.89-$ $6.81(\mathrm{~m}, 2 \mathrm{H}), 6.05(\mathrm{~s}, 1 \mathrm{H}), 5.78(\mathrm{~s}, 2 \mathrm{H}), 5.32(\mathrm{~s}, 2 \mathrm{H}) .{ }^{13} \mathrm{C}$ NMR $(101$ $\left.\mathrm{MHz}, \mathrm{CDCl}_{3}\right) \delta 160.06,157.52,156.69,152.11,148.21,147.44$, $145.97,143.39,130.57,130.18,129.54,128.45,127.68,124.67$, 123.44, 122.39, 121.02, 115.30, 114.94, 114.09, 113.70, 112.08,
101.02, 63.48, 55.96, 50.90; IR (KBr) $\nu$ : 2926, 1733, 1635, 1505, 1457, 1388, 1253, 1150, 1074, $1026 \mathrm{~cm}^{-1}$; HRMS (ESI) calcd for $\mathrm{C}_{28} \mathrm{H}_{22} \mathrm{~N}_{3} \mathrm{O}_{5}[\mathrm{M}+\mathrm{H}]^{+} 480.1554$, found 480.1539 .

3.1.9.15 5-((4-((4-Methoxyphenoxy)methyl)-1H-1,2,3-triazol-1yl)methyl)-3-phenyl-7H-furo[3,2-g]chromen-7-one (8o). Yield 88\%, light yellow solid, mp $195-197{ }^{\circ} \mathrm{C} ;{ }^{1} \mathrm{H}$ NMR (400 $\mathrm{MHz}, \mathrm{CDCl}_{3}$ ) $\delta 8.04(\mathrm{~s}, 1 \mathrm{H}), 7.86(\mathrm{~s}, 1 \mathrm{H}), 7.71(\mathrm{~s}, 1 \mathrm{H}), 7.60-7.50(\mathrm{~m}, 5 \mathrm{H}), 7.48-$ $7.41(\mathrm{~m}, 1 \mathrm{H}), 6.93(\mathrm{~d}, J=9.1 \mathrm{~Hz}, 2 \mathrm{H}), 6.84(\mathrm{~d}, J=9.1 \mathrm{~Hz}, 2 \mathrm{H})$, $6.03(\mathrm{~s}, 1 \mathrm{H}), 5.79(\mathrm{~s}, 2 \mathrm{H}), 5.19(\mathrm{~s}, 2 \mathrm{H}), 3.77$ (s, 3H). ${ }^{13} \mathrm{C}$ NMR (101 $\left.\mathrm{MHz}, \mathrm{CDCl}_{3}\right) \delta 160.07,157.50,154.47,152.19,151.82,148.25$, $143.46,130.57,129.54,128.46,127.67,124.67,122.51,116.29$, $116.08,115.20,114.84,114.00,113.67,101.06,62.88,55.79$, 50.98; IR (KBr) v: 2927, 1717, 1631, 1574, 1439, 1388, 1257, 1151, 1082, $1109 \mathrm{~cm}^{-1}$; HRMS (ESI) calcd for $\mathrm{C}_{28} \mathrm{H}_{22} \mathrm{~N}_{3} \mathrm{O}_{5}[\mathrm{M}+\mathrm{H}]^{+}$ 480.1554 , found 480.1570 .

\subsection{Biological activity}

3.2.1 Cell cultures. The murine B16 melanoma cell line was purchased from Chinese Academy of Sciences (Beijing, China). The cells were maintained in Dulbecco's Modified Eagle's Medium (DMEM, Gibco Life Technologies, France) supplemented with $10 \%(\mathrm{v} / \mathrm{v})$ FBS, penicillin $\mathrm{G}\left(100 \mathrm{U} \mathrm{mL}^{-1}\right)$ and streptomycin (100 mg mL ${ }^{-1}$ ) (Gibco-BRL, Grand Island, NY, USA) in $5 \% \mathrm{CO}_{2}$ at $37{ }^{\circ} \mathrm{C}$.

3.2.2 Cell viability measurement. The cell viability was assayed by adding CCK-8 solution. Generally speaking, the B16 cells were seeded in 96-well plates at a density of $8 \times 10^{3}$ cells per well and allowed to adhere for $24 \mathrm{~h}$. The medium was replaced with medium containing samples diluted to the appropriate concentrations. The control cells were treated with DMSO at a final concentration of $0.1 \%$. After $24 \mathrm{~h}$, the culture medium of the cells was discarded, $10 \mu \mathrm{L}$ of CCK- 8 solution was added into each well and cells were incubated at $37{ }^{\circ} \mathrm{C}$ for another $2 \mathrm{~h}$. The absorbance was measured at $450 \mathrm{~nm}$ using a Spectra Max M5 (Molecular Devices, USA). All assays were performed in triplicate. Absorbance of cells without treatment was regarded as $100 \%$ of cell survival. Cell viability was calculated using the following formula: cell viability $(\%)=\left(A_{\text {sample }} /\right.$ $\left.A_{\text {control }}\right) \times 100 \%$.

3.2.3 Melanin measurement. B16 cells were seeded at a density of $2 \times 10^{5}$ cells per well in a 6 -well plate. After overnight incubation, test samples were added to individual wells, cells were incubated for $48 \mathrm{~h}$ and washed twice with ice-cold PBS. After cells lysed, the harvested cells were centrifuged, and the pellet was dissolved by adding $1 \mathrm{~N} \mathrm{NaOH}$, followed by incubation at $80{ }^{\circ} \mathrm{C}$ for $1 \mathrm{~h}$. Each lysate $(150 \mu \mathrm{L})$ was put in a 96 well microplate, and measured spectro-photometrically at $405 \mathrm{~nm}$ by a multi-plate reader. Protein concentration of each sample was determined by BCA Protein Assay Kit (Biomed, Beijing). Intracellular melanin amount expressed as abs per $\mu \mathrm{g}$ protein was shown as a percentage value. The percentage value of the samples treated cells was calculated with respect to the untreated cells.

3.2.4 Tyrosinase activity assay. The assay for tyrosinase activity was carried out as previously described, with a slight modification. ${ }^{37}$ B16 cells were seeded in a 6-well plate at 
a density of $2 \times 10^{5}$ cells per well and allowed to attach for $24 \mathrm{~h}$. Test samples were then added to individual wells. After a $24 \mathrm{~h}$ incubation, cells were washed with ice-cold PBS twice, lysed with $1 \%$ Triton $\mathrm{X}-100$ solution containing $1 \%$ sodium deoxycholate for $30 \mathrm{~min}$ at $-80{ }^{\circ} \mathrm{C}$, each lysate was centrifuged at $12000 \mathrm{~g}$ for $15 \mathrm{~min}$ to obtain the supernatant. After protein quantification and adjustment, $90 \mu \mathrm{L}$ of the supernatant was incubated in duplicate with $10 \mu \mathrm{L}$ of freshly prepared substrate solution (10 mM L-DOPA) in a well of a 96-well plate. Then the cells were incubated at $37^{\circ} \mathrm{C}$ in dark for $60 \mathrm{~min}$, the absorbance was measured at $490 \mathrm{~nm}$ and the samples treated cells was presented as percentage against the untreated cells.

\section{Conclusions}

In summary, a novel series of furocoumarin derivatives bearing 1,2,3-triazole had been prepared via click chemistry. Two of them $(\mathbf{8 a}, \mathbf{8 0})$ could not only promote the melanin synthesis, but also the tyrosinase activity in vitro than positive control (8-MOP) in a concentration dependent manner, and the SAR was summarized. In light of our findings, it may provide scientific guidance for further structural modification of the furocoumarin, even if without knowing the specific targets of the disease. Further studies on action mechanism and animal experiment on transgenic mouse is under way.

\section{Conflicts of interest}

There are no conflicts to declare.

\section{Acknowledgements}

This research was financially supported by the Xinjiang Key Laboratory of Xinjiang Indigenous Medicinal Plants Resource Utilization (No. 2018D04020); Funds for the Foundation of Director of XTIPC, CAS (2016TP001); Natural Science Foundation of Xinjiang, China (No. 2017D01A76).

\section{Notes and references}

1 K. Ezzedine, V. Eleftheriadou, M. Whitton and N. van Geel, Lancet, 2015, 386, 74-84.

2 M. Rodrigues, K. Ezzedine, I. Hamzavi, A. G. Pandya and J. E. Harris, J. Am. Acad. Dermatol., 2017, 77, 1-13.

3 K. Ezzedine, H. W. Lim, T. Suzuki, I. Katayama, I. Hamzavi, C. C. E. Lan, B. K. Goh, T. Anbar, C. Silva de Castro, A. Y. Lee, D. Parsad, N. van Geel, I. C. Le Poole, N. Oiso, L. Benzekri, R. Spritz, Y. Gauthier, S. K. Hann, M. Picardo and A. Taieb, Pigm. Cell Melanoma Res., 2012, 25, E1-E13.

4 N. C. Laddha, M. Dwivedi, M. S. Mansuri, A. R. Gani, M. Ansarullah, A. V. Ramachandran, S. Dalai and R. Begum, Exp. Dermatol., 2013, 22, 245-250.

5 S. Wang, R. Jin, R. Wang, Y. Hu, X. Dong and A. Xu, RSC Adv., 2016, 6, 106308-106315.

6 J. M. Richmond, M. L Frisoli and J. E. Harris, Curr. Opin. Immunol., 2013, 25, 676-682.
7 P. Meredith and J. Riesz, Photochem. Photobiol., 2004, 79, 211-216.

8 M. Sandoval-Cruz, M. García-Carrasco, R. Sánchez-Porras, C. Mendoza-Pinto, M. Jiménez-Hernández, P. MunguíaRealpozo and A. Ruiz-Argüelles, Autoimmun. Rev., 2011, 10, 762-765.

9 M. M. Garcia-Molina, J. L. Muñoz-Muñoz, F. Garcia-Molina, P. A. García-Ruiz and F. Garcia-Canovas, J. Agric. Food Chem., 2012, 60, 6447-6453.

10 Q. Wu, Z. Xu, Y. Duan, Y. Zhu, M. Oua and X. Xu, RSC Adv., 2017, 7, 28114-28123.

11 M. L. Felsten, A. Alikhan and V. Petronic-Rosic, J. Am. Acad. Dermatol., 2011, 65, 493-514.

12 W. Damsky and B. A. King, J. Am. Acad. Dermatol., 2017, 76, 736-744.

13 J. E. Harris, M. Rashighi, N. Nguyen, A. Jabbari, G. Ulerio, R. Clynes, A. M. Christiano and J. Mackay-Wiggan, J. Am. Acad. Dermatol., 2016, 74, 370-371.

14 W. L. Fowucs, D. G. Griffith and E. L. Oginsky, Nature, 1958, 18, 571-572.

15 T. B. Fitzpatrick, J. A. Parrish and M. A. Pathak, in Phototherapy of vitiligo (idiopatic leukodermia) in sunlight and man, Tokyo University Press, 1974, pp. 365-398.

16 L. M. Felsten, A. Alikhan and V. Petronic-Rosic, J. Am. Acad. Dermatol., 2011, 65, 473-491.

17 S. Tippisetty, D. Goudi, A. W. Mohammed and P. Jahan, Toxicol. In Vitro, 2013, 27, 438-440.

18 A. Guiotto, P. Rodighiero, P. Manzini, G. Pastohi, F. Bordin, F. Baccichetti, F. Carlassare, D. Vedaldi, F. Dall'Acqua, M. Tamaro, G. Recchia and M. Cristofolinis, J. Med. Chem., 1984, 27, 959-967.

19 H. Matsuda, N. Hirata, Y. Kawaguchi, M. Yamazaki, S. Naruto, M. Shibano, M. Taniguchi, K. Baba and M. Kubo, Biol. Pharm. Bull., 2005, 28, 1229-1233.

20 E. Chodurek, A. Orchel, J. Orchel, S. Kurkiewicz, N. Gawlik, Z. Dzierżewicz and K. Stęppień, Cell. Mol. Biol. Lett., 2012, 17, 616-632.

21 C. Niu, G. X. Pang, G. Li, J. Dou, L. F. Nie, H. Himit, K. Kabas and H. A. Hisa, Bioorg. Med. Chem., 2016, 24, 5960-5968.

22 L. Yin, G. X. Pang, C. Niu, J. Dou and H. A. Aisa, Int. J. Mol. Med., 2018, 41, 3727-3735.

23 C. Niu, D. Zang and H. A. Aisa, Chem. Res. Chin. Univ., 2018, 34, 408-414.

24 C. Niu and H. A. Aisa, Molecules, 2017, 22, 1303-1330.

25 P. Yadav, K. Lal, A. Kumar, S. K. Guru, S. Jaglan and S. Bhushan, Eur. J. Med. Chem., 2017, 126, 944-953.

26 N. Pribut, C. G. L. Veale, A. E. Basson, W. A. L. van Otterlo and S. C. Pelly, Bioorg. Med. Chem. Lett., 2016, 26, 3700-3704.

27 S. Maračić, T. G. Kraljević, H. Č. Paljetak, M. Matijašić, D. Verbanac, M. Cetina and S. Raić-Malić, Bioorg. Med. Chem., 2015, 23, 7448-7463.

28 N. Fu, S. Wang, Y. Zhang, C. Zhang, D. Yang, L. Weng, B. Zhao and Li. Wang, Eur. J. Med. Chem., 2017, 136, 596602.

29 N. S. Vatmurge, B. G. Hazra, V. S. Pore, F. Shirazi, P. S. Chavan and M. V. Deshpande, Bioorg. Med. Chem. Lett., 2008, 18, 2043-2047. 
30 B. L. Zhang, C. Q. Fan, L. Dong, F. D. Wang and J. M. Yue, Eur. J. Med. Chem., 2010, 45, 5258-5264.

31 E. C. Gaudino, S. Tagliapietra, K. Martina, G. Palmisanob and G. Cravotto, RSC Adv., 2016, 6, 46394-46405.

32 A. Chilin, P. Manzini, S. Caffieri, P. Rodighiero and A. Guiotto, J. Heterocycl. Chem., 2001, 38, 431-434.

33 Q. Shen, Q. Peng, J. L. Sha, X. Liu, Z. Huang, X. Pu, L. Ma, Y. M. Li, A. S. C. Chan and L. Gu, Eur. J. Med. Chem., 2005, 40, 1307-1315.
34 R. O. Schönleber, J. Bendig, V. Hagen and B. Giese, Bioorg. Med. Chem., 2002, 10, 97-101.

35 Y. Hu, H. Shen, X. Zhang, Y. Liu and X. Sun, RSC Adv., 2018, 8, 23252-23256.

36 S. Y. Park, M. L. Jin, Y. H. Kim, Y. Kim and S. J. Lee, Arch. Dermatol. Res., 2011, 303, 737-744.

37 H. J. Kim, J. S. Kim, J. T. Woo, J. T. Woo, I. S. Lee and B. Y. Cha, Acta Biochim. Biophys. Sin., 2015, 47, 548-556. 